Филос. науки / Russ. J. Philos. Sci. 2019. 62(2)

ИСТОРИЯ ФИЛОСОФИИ. СОВРЕМЕННЫЙ ВЗГЛЯД

Философская мысль

в диалоге и полемике

Л.Н. Толстой:

Просветитель, преодолевший Просвещение*

\title{
С.М. Климова
}

Национальный исследовательский университет «Высшая школа экономики», Москва, Россия

DOI: $10.30727 / 0235-1188-2019-62-2-109-126$

Оригинальная исследовательская статья

\section{Аннотация}

В статье рассматриваются взгляды Л.Н. Толстого в качестве не только яркого представителя, но и завершителя эпохи Просвещения. Сопоставление его идей с философией Спинозы и Дидро позволяет прояснить некоторые аспекты произошедшего в этом завершении перехода к уникальному толстовскому религиозно-философскому учению. Специальному анализу подверглись общие и специфические черты трех философов. Особое внимание уделено способу мышления, представленному в учении Толстого, Спинозы и Дидро, их отношению к науке, специфике их мировоззрения. Важным аспектом понимания стало раскрытие противоречия между образом мыслей и образом жизни трех философов. Исследована природа творческого мышления в их философии. У Дидро она описана через концепт парадоксализма, у Спинозы - через понятие целостности, у Толстого - через метод сцепления, обнаруженный им в литературном творчестве. Если для европейских просветителей образ мышления напрямую связан с природой человека, представленный как единство natura naturans и natura naturata, то для Толстого важнее всего некое априорное чувство жизни, пропитанное верой в Бога и инстинктом самоотдачи - любви к Высшему и другим людям. Метод сцепления уводит Толстого от прямого продолжения просветительских идей, делая значимым обращении не только к разуму, но и к творческой интуиции. Показан переход Толстого от рационального восприятия жизни к ее религиозным

\footnotetext{
* Исследование выполнено за счет гранта Российского научного фонда (проект №19-18-00100).
} 
и экзистенциальным основаниям. Толстой постепенно уходит от идеи природного человека к идее человека, живущего по заповедям Христа. Показано, что начав с просветительского мировоззрения, Толстой заканчивает созданием религиозно-философского учения, характерного для начала XX века.

Ключевые слова: Толстой, Спиноза, Дидро, Просвещение, просветитель, религиозное сознание, мировоззрение, способ мышления.

Климова Светлана Мушаиловна - доктор философских наук, профессор Школы философии Национального исследовательского университета «Высшая школа экономики».

sklimova@hse.ru

https://orcid.org/0000-0003-0974-552X

Для цитирования: Климова С.М. (2019) Л.Н. Толстой: Просветитель, преодолевший Просвещение // Философские науки. 2019. Т. 62. № 2. C. 109-126. DOI: 10.30727/0235-1188-2019-62-2-109-126

\title{
L.N. Tolstoy: The Enlightener Who Overcame the Enlightenment*
}

\author{
S.M. Klimova \\ National Research University Higher School of Economics, Moscow, \\ Russia
}

DOI: $10.30727 / 0235-1188-2019-62-2-109-126$

Original research paper

\begin{abstract}
The article considers L.N. Tolstoy not only as a thinker who represents but also accomplishes Enlightenment. Through a comparison of his ideas with philosophy of Spinoza and Diderot, the author clarifies the aspects of the transition from Enlightenment to the unique Tolstoy's religious and philosophical doctrine. A special attention is paid to the way of thinking, the relation to science and the specifics of the worldview of Tolstoy and Diderot. The contradiction between the way of thinking and the way of life of the three philosophers is revealed. The author also researches their philosophical interpretations of the nature of creative thought. Diderot describes the nature through the concept of paradoxism, Spinoza describes it with the concept of integrity, and Tolstoy uses the method of cohesion that he founds in literary works. If for the philosophers of European Enlightenment,
\end{abstract}

* The research has been funded by the grant of the Russian Science Foundation (RSF) (project no. 19-18-00100). 
the way of thinking is directly related to human nature, which is presented as a unity of natura naturans and natura naturata, then Tolstoy considers that the most important is a certain a priori sense of life, which is imbued with faith in God and with an instinct of self-giving that is love for the Supreme and other people. The method of cohesion leads Tolstoy away from the direct continuation of educational ideas, stressing the significance of appealing not only to reason but also to creative intuition. Tolstoy gradually moves away from rational perception of Life to its religious and existential foundations. Tolstoy's worldview undergoes transition from the idea of a natural man to the idea of a human being who lives by commandments of Christ. Starting from the worldview of Enlightenment, Tolstoy comes to the creation of religious and philosophical doctrine, which is relevant to early $20^{\text {th }}$ century.

Keywords: Tolstoy, Spinoza, Diderot, Enlightenment, Enlightener, religious consciousness, worldview, mode of thought.

Svetlana Klimova - D.Sc. in Philosophy, Professor at the School of Philosophy, National Research University Higher School of Economics.

sklimova@hse.ru

https://orcid.org/0000-0003-0974-552X

For citation: Klimova S.M. (2019) L.N. Tolstoy: The Enlightener Who Overcame the Enlightenment. Russian Journal of Philosophical Sciences $=$ Filosofskie nauki. Vol. 62, no. 2. pp. 109-126. DOI: 10.30727/0235-1188-2019-62-2-109-126

\section{Введение}

Литературовед Б. Эйхенбаум назвал Л.Н. Толстого «канонизатором кризиса», показав, что «обличительные, разрушительные силы скрыты почти в каждом его приеме. Толстой - не зачинатель, а завершитель» [Эйхенбаум 2009, 138]. Одним из примеров такого завершения стало отношение Толстого к эпохе Просвещения [Israel 2001; Паперно 2018; Шульц 2013]. Культ разума, который навсегда оставался для Толстого важнейшим мерилом истины, зачастую для многих означал его приверженность самому Просвещению. «...[Р]азум - это тот закон, по которому должны жить неизбежно разумные существа - люди < . . > в себе же мы знаем этот закон, как то, что мы сами должны совершить» [ПСС 26, 348].

С этой точки зрения сопоставление Толстого с двумя яркими представителями Просвещения - родоначальником эпохи Б. Спинозой [Климова 2013, 71-81], который, по словам Дж. Израэля, создал «радикальный хребет европейского Просвещения» [Israel 2001, iii], и одним из представителей французского Про- 
Филос. науки / Russ. J. Philos. Sci. 2019. 62(2) Философская мысль в диалоге и полемике свещения Д. Дидро [Bozovic 2018, 77-93] - позволяет наглядно высветить не только черты толстовского просветительского ума «завершителя», но и прояснить некоторые аспекты произошедшего в этом завершении перехода к уникальному толстовскому религиозно-философскому учению.

\section{Спиноза, Дидро, Толстой}

Предлагаемое сравнение раскрывает ряд сходных черт и характеристик трех мыслителей. Спинозу Толстой считал одним из мощнейших теоретиков Нового времени, искренне восхищаясь его способности видеть целое, уметь из разнородных частей создать объемную картину всестороннего понимания предмета. Толстого, как и многих других мыслителей, не устроила система Спинозы, его страсть к геометрии, которая привела к странному соединению этики и математики. «Странность», конечно, с точки зрения Толстого. Он писал, что Спиноза свое великолепное учение о должном запаковал «в несвойственную... форму математического сочинения» [ПСС 27, 54]. С Дидро же он выстроил совсем иные философские взаимоотношения и иной «эпохальный диалог». Несмотря на то, что последний не входил в число его любимых мыслителей (1), между ними, безусловно, существовало и внутреннее сопряжение, и просветительская близость. Прежде всего, речь идет об оппозиции у обоих естественных наук и гуманитарных (в частности, философии). У Дидро, по словам Т.Б. Длугач, «философское мышление с самого начала не совпадает с естественнонаучным, имея своим предметом тот парадоксальный остаток, который предстает после научного анализа» [Длугач 1975, 62].

Отрицательное отношение Толстого к наукам хорошо известно. Дидро несомненно повлиял на некоторые аспекты его критики естественнонаучного знания. Например, Толстой подчеркивает важность и новизну идеи предела и полезности наук, почерпнутую из книги Дидро «Избранные сочинения. Издание к столетию со дня смерти. 30 июля 1884 г.». При этом он разделяет с французским философом представление о полезности философии для народа. Речь идет об идеи Дидро, согласно которой «все определяется полезностью. Именно полезность через несколько веков определит границы экспериментальной физики, подобно тому, как это происходит сейчас с геометрией... Есть только одно средство расположить простой народ к философии; оно состоит в 
том, чтобы показать ее пользу» [Дидро 1986, 337, 341]. Эти идеи будут неоднократно повторяться и в русской философии в целом, и конкретно в популярных толстовских текстах.

Некоторая общность между Толстым и Дидро наблюдается при характеристике их способов мышления, основанных не на абстрактном философском теоретизировании, а на художественности и парадоксальности, выявляемой через схожую для обоих литературную форму изложения идей. Наконец, сближает их и представление о природе творческого мышления. Парадоксализм Дидро направлен на обнаружение противоречивой природы человеческого мышления; «метод сцепления» Толстого - на категорию жизни в ее экзистенциальном и не менее парадоксальном восприятии и интерпретации.

Но даже не детализируя общность Толстого с данными просветителями, совершенно очевидно, что в их судьбах отражена не только теоретическая связь, но и эпохальная близость. Во-первых, Толстой - достойный продолжатель идеи Просвещения о примате разума над всеми другими формами познания и описания, в том числе и религиозными. «Перемены наши происходят не через общение с людьми (такие перемены внешние), а через общение с Богом, с разумением, через общение с мыслью, с истиной, через углубление в нее. Мысль человека, сознание его - это тот рычаг, которым человек поворачивается» [ПСС 90, 262]. В письме к Н.А. Руковишникову от 4 февраля 1909 г., он признавался, что «жизнь - серьезное дело, а в жизни самое серьезное - религия, т.е. то, как человек понимает себя и свое отношение ко всему, к богу. И потому опасно и губительно делать из религии средство для достижения каких-либо не говорю уже корыстных, самолюбивых или тщеславных, но и каких бы то ни было эгоистических целей, вроде душевного спокойствия. Цель религии может быть только одна: познание доступной человеку высшей истины и подчинение ей своей жизни» [ПСС 79, 58]. Если мы подставим в данном случае вместо толстовской «цели религии» «цель философии», то эти же слова станут «истиной» Спинозы или Дидро: «Целью религии, которая исходит от бога, может быть только познание необходимых истин и отправление основных обязанностей. Религия была бы недостойна бога и человека, если бы она преследовала другую цель» [Дидро 1986, 188].

Во-вторых, все они - представители идейно-религиозного радикализма [Israel 2001, 4-23], весьма неоднородного, но имеющего 
общую тенденцию критического (реформационного) мировосприятия, отраженного, прежде всего, в их жизненных историях, судьбах, мировоззренческих и философских позициях. Bсе трое были публично осуждены за «потрясение общественных устоев». В 1656 г. Спиноза был подвергнут так называемому «великому херему» со стороны своей еврейской общины. Собрание правоверных иудеев придало его абсолютному отлучению, ему было запрещено общаться с любым евреем, он навсегда был изгнан из общины. Нечто похожее случилось с Л.Н. Толстым, который определением Святейшего Синода в феврале 1901 г., как будто, «отторг себя сам от всякого общения с церковью православной»; таким образом, был признан «факт его отпадения от Церкви» [Церковные ведомости 1901, 45-47]. Дидро, всю жизнь был изгоем в своей стране; его труды уничтожалась или запрещались - критика церковной курии жестко пресекалась властями. В. Асмус в предисловии к 23-му тому указал на эту близость троих: «В день опубликования постановления Синода Толстой стал в сознании культурных людей всего мира в один ряд с такими борцами и деятелям независимой мысли, каким был Спиноза, какими были французские просветители» [ПСС 23, XXVIII].

В-третьих, их жизненный радикализм заключен и в трагическом противоречии между образом жизни и образом мыслей философскими идеями: Спиноза, Дидро и Толстой ясно понимали «пустошность» внешней жизни по сравнению с внутренней, к которой европейские мыслители относили главным образом занятия философией, а Толстой - поиск практического пути к открытию «смысла жизни», христианской «любви ко всем»и своему собственному «внутреннему росту».

Спиноза предстает в этом плане наиболее изельной личностью, мало подверженной воздействию «извне». Цельность означала единство жизни и образа мыслей, твердость убеждений и право на их обоснование собственным поведением. «Всю жизнь он делал только то, что считал нужным, и все, что считал нужным, - обязательно делал. Это редкое совпадение мысли и дела, теории и практики, учения и жизни внушает впечатление исключительной цельности и тогда, когда от жизни Спинозы обращаешься к его теории» [Асмус 1971, 36]. Однако и он долго воздерживался от «ухода»: «Философия и занятия делом, религией, политикой, как заметил Спиноза, просто не смешиваются» [Israel 2001, 165]. При этом он реалистически понимал липкость все- 
го того, что связано с властью, богатством, удовольствиями жизни [Спиноза 1957, 321].

Дидро более двойственен: хотя он много времени посвятил напряженным поискам собственного жизненного пути, формируя и оттачивая свой «энциклопедический ум», ему приходилось перебиваться случайными заработками. Он отдавал все свои силы занятиям философией, историей, литературой и т.д., но ему вовсе не были чужды плотские радости и удовольствия буржуазной эпохи, более того, в его жизнелюбии заключен весь «специфический аромат» французского «просвещения» (как синонима раскрепощения и эмансипации природного эгоистического человека, не отягощенного упреками совести кающегося грешника).

Природа двойственности Дидро вполне соответствует представлению о природе человека, представленному в его философии. «Основой просветительских взглядов стало понятие “естественный человек”; но само “естественное”, “природное”, <..> оказывается сложным, двойственным, противоречивым, и истоки этого противоречия - в спинозовском понимании природы как единства natura naturans и natura naturata. C точки зрения французских материалистов, воспринявших спинозовский принцип, творящая природа (natura naturans) существует как некое целое, но, будучи в то же время сотворенной природой (natura naturata), она многообразна и состоит из частей, что предполагает их взаимодействие. Ни одна часть не может существовать, не будучи связанной с другими; поэтому следует признать разумным такой порядок, который соответствует не только данной индивидуальной природе, но и природе других частей, всего целого» [Длугач 1975, 46].

Вслед за разделением человека на «порождающее начало» natura naturans - и «порожденное» (социальность) - natura naturataпрактически все они представляют человека как эгоцентрика, который, однако, способен к совместному бытию с другими людьми, когда он опирается на общепринятые (конвенциональные) законы и принципы общественной морали. В этом разумном эгоизме уже заложены базовые основы как западного утилитаризма, так и отечественного «разумного эгоизма», которые очень скоро придут на смену романтическим идеям Просвещения. Они и сами стали примерами «новых людей», сочетающих «Эго» и общественные добродетели в своей личной жизни. 


\section{Толстой: в чем его вера}

Трагичнее всех выглядит фигура «завершителя» эпохи Толстого как наиболее противоречивого мыслителя, гениального писателя и борющегося с самим собой человека. Всю жизнь он разрывался «внутри себя», пытался вырваться, избавиться: от сладости «двух капель меда - семьи и писательства»; от внутреннего антиномизма между своим «духовным» человеком и «животным»; от невозможности жить, веря лишь в себя, в свою душу, и от невозможности жить по правилам, навязываемым внешним миром и другими людьми.

Он искал разные способы «избавления» от искусственности «всего»: «ничтожной» деятельности писателя, барской роскоши и праздности высшего круга, мелочности семейных забот, чтобы «опростать место для сокровенного» - Бога, развивая своего духовного человека - смиренного работника, ожидающего «зова» Хозяина, чтобы радостно ответить: «Иду!» [ПСС 29, 43]. Он был «пойман миром в сети», которые так и не сумел разорвать. Его «Дневники», особенно последних лет, напоминают безысходно трагический «плач» одинокого старика, всеми преследуемого и втянутого в бесконечные позорные мелочные игры и житейские интриги: «24 Сен. Они разрывают меня на части <..>. 27 Сен. Как комично то противуположение, в котором я живу, в котором без ложной скромности: вынашиваю и высказываю самые важные, значительные мысли, и рядом с этим: борьба и участие в женских капризах, и которым посвящаю большую часть времени» [ПСС 58, 138]. И сделать-то ничего было нельзя. Как далека от рациональной стройности и логической безаппеляционности трагедия его сердца и ума. «В теперешнем положении моем, едва ли не главное нужное - это неделание, неговорение. Сегодня живо понял, что мне нужно только не портить своего положения и живо помнить, что мне ничего, ничего не нужно» [ПСС 58, 129].

Бесконечная тоска, которая в конечном итоге вовсе не пошлобытовая, мелочная, но тоска по вечности, по желанию и нежеланию любить «ближнего», по непримиренности с временным и сиюминутным и одновременным осознанием только этого временного и сиюминутного - жизни «здесь и сейчас»; тоска всепонимающего сердца, переходящая в молитвенное заклинание души. «Ради Бога, хоть не Бога, но ради самих себя, опомнитесь. Поймите все безумие своей жизни. Хоть на часок отрешитесь $<. .>$ Хоть на часок оторвитесь < .. > Только опомнитесь на часок, и вам 
ясно будет, что важное, одно важное в жизни - не то, что вне, а только одно то, что в нас, что нам нужно. Только поймите то, что вам ничего, ничего не нужно, кроме одного, спасти свою душу и что только этим мы спасем мир. Аминь» [ПСС 58, 177-178].

Все сказанное демонстрирует как раз отличие толстовского взгляда на природу человека от просветительского; он не приемлет очевидностей голого эгоистического разума; ему кажутся пустяком и женской истерикой вполне определенные разумной природой человека желания: иметь собственность, жить во имя себя и близких, требовать к себе внимания и любви, - обычная повседневная, логически и прагматически обоснованная жизнь. Дело в том, что не эгоизм и natura naturans человека являются, с его точки зрения, действительно его порождающими началами, а некое особое чувство жизни, пропитанное верой в Бога и инстинктом самоотдачи - любви к Высшему и другим людям. Человека эгоистом, напротив, делает natura naturata - социум, семья, потребности жизни для себя и комфортного существования в мире других как обособленного и нравственно необременяющего мое «Я». Это «Я» ученого, богослова, врача или юриста - всех, видящих в себе «исключительную личность», особенное существо, отличное от всех других и претендующее на какой-то особый статус в мире других людей. Формула просветителей переворачивается полностью в мировоззрении Толстого. Но подлинное «Я» - это сущность человека, оно одно во всех людях и раскрывается в любовном движении навстречу друг другу в простых действиях взаимопомощи, поддержки, жизни по Христу.

Просвещение, попав в исследовательскую оптику Толстого, становится лишь «материалом» для особого личного «переживания» не только на основе законов сознания, но и законов сердца или общих чувств, которые питают и формируют жизнь. Сознание проявление индивидуального закона, основанного на свободе моей воли. «Каковы бы ни были общие законы, управляющие миром и человечеством, бесконечно малый момент свободы всегда неотьемлемо принадлежит мне <..> с точки зрения сознания жизни, мы чувствуем в самих себе ту силу, которая производит все существующее» [ПСС 15, 239, 244].

Субстратность законов сердца или общих чувств определена религиозными переживаниями, присущими субъекту. Венчающее их научно-теоретическое и художественно-эстетическое осмысление происходит через интроспективное сопряжение 
жизненного и рационального в творчестве писателя. «Сердце указывает, что любить, а потом о чем думать и что изучать» (курсив мой. - C. К.) [ПСС 58, 160]. Для Толстого тождество и взаимозависимость разумной и сердечной основ познания есть необходимая предпосылка для реализации религиозной работы души каждого человека.

Толстой проверяет любую мысль на ее жизнеспособность таким мерилом, как «общее чувство». Оно не сливается и не сводится к отдельным чувствам, но является особенным состоянием сознания жизни, позволяет пережить и понять чужую идею или эпоху как свою собственную, а свою - сделать близкой и уродненной для других: «Я желал чего-то высокого и хорошего; но чего, я передать не могу; хотя и ясно сознавал, чего я желаю. - Мне хотелось слиться с Существом всеобъемлющим. Я просил Его простить преступления мои; но нет, я не просил этого, ибо я чувствовал, что ежели Оно дало мне эту блаженную минуту, то оно простило меня. Я просил, и вместе с тем чувствовал, что мне нечего просить, и что я не могу и не умею просить. Я благодарил Его, но не словами, не мыслями. Я в одном чувстве соединял все, и мольбу, и благодарность. <..> Ни одного из чувств - Веры, Надежды и Любви я не мог бы отделить от общего чувства» [ПСС 46, 62].

Идея «общего чувства» инкорпорирована в «формулу творчества» Толстого, основанную на принципе особого «сцепления», предназначенного собирать мысли между собой, хотя оно «само... составлено не мыслью, (я думаю), а чем-то другим, и выразить основу этого сцепления непосредственно словами никак нельзя; а можно только посредственно - словами описывая образы, действия, положения» [ПСС 62, 268]. Это «общее чувство» или толстовское «сцепление» позволяют определить наше сознание как интуицию религиозного чувства жизни, данную нам до начала рационального осмысления и понимания, но в непосредственной связи с ним. А это уже шаг в ХХ в. с идеями нуминозного опыта (Р. Отто) и опытом его экзистенциального переживания.

Свет истины, озарявший многих героев произведений Толстого, как правило, был результатом наложения двух типов знания. С одной стороны, они имеют интуитивное - звуковое или визуальное обнаружение Бога через свет - вспышку, озарение, образ. С другой стороны, описан процесс разумного постижения 
(«теперь знаю») Бога как смысла и назначения Жизни. Этот переход от интуиции к знанию истины зачастую дан через сон состояние моментального постижения истины и смысла. «Вдруг радость совершается: приходит тот, кого он ждал <...>. Он пришел и зовет его, и этот, тот, кто зовет его, тот самый, который кликнул его и велел ему лечь на Никиту. И Василий Андреич рад, что этот кто-то пришел за ним. “Иду!” - кричит он радостно, и крик этот будит его. И он просыпается, но просыпается совсем уже не тем, каким он заснул. <.. > Не знал, так теперь знаю. Теперь уж без ошибки. Теперь знаю» [ПСС 29, 43]. Так описано открытиеозарение героя рассказа «Хозяин и работник» перед встречей с вселюбящим Хозяином - Богом.

Но эта встреча и откровение истинной жизни не дается никому даром, в простом акте озарения или вещего сна. Надо постоянно переживать жизнь (переосмысливать и переоценивать протекающую в тебе жизнь), совершая добро, учась любить людей, то есть реализуя не внешние предписания, но внутренние моральные нужды человека, когда «всякий добрый поступок увеличивает истинное благо моей вечной жизни, а всякий злой поступок уменьшает его» [ПСС 34, 249]. И вновь в религиозном мировоззрении проступают отголоски просветительского умонастроения Толстого.

В итоге его учение содержит ряд рациональных и религиозных посылок. Уход от своего голого разума и своего особенного эго к общему «Я», к жизненной вере, а через нее к другому человеку (людям) и миру возможен лишь на пути соединения разума и веры в акте морально-практического императива - жизни по Христу. Ядром становится религиозное чувство, вбирающее в себя субъективный мир собственных переживаний, концентрируемый, однако, в переживании Другого: Бога, веры, любви, жизни не для себя. «Чувство это есть любовь. Жизнь есть деятельность животной личности, подчиненной закону разума. Разум есть тот закон, которому для своего блага должна быть подчинена животная личность человека. Любовь есть единственная разумная деятельность человека» [ПСС 26, 383].

В этом смысле настоящим делом занят тот, кто не просто живет, но каждую минуту ищет общий - для себя и других - смысл жизни. А это - удел религиозного человека, мыслителя не по профессии, а по внутреннему мироустройству. Для Толстого речь идет о духовно-нравственной личности, суть которой не во 

внешней работе ума (творчества), а во внутренней работе души. «Не только в художественных, но и научных философских сочинениях, как бы он ни старался быть объективен - пускай Кант, пускай Спиноза, - мы видим, я вижу душу только, ум, характер человека пишущего» [Толстой, Страхов 2003, 913].

С точки зрения Толстого, душа и ум Спинозы были обращены к Богу, как бы тот его не номинировал - Природой, Разумом или Этикой. В этом смысле любого философа можно назвать религиозным, ибо очерченный Толстым исследовательский круг можно обнаружить в любых текстах того времени.

Перед нами пример особенного толстовского переживания «предметов философии»: во-первых, ни один из них нельзя рассматривать как объект научного знания, расчленяемый на составные части для извлечения смыслов с помощью определенных методов познания; во-вторых, все философские понятия даны нам как целостность, которую мы схватываем непосредственно, исходя из сознания собственного «Я»: «Мое тело, моя душа, моя жизнь, моя смерть, мое желание, моя мысль, мне больно, мне дурно, мне хорошо, мне радостно, всегда одни и те же и не могут быть ни яснее, ни темнее ни для дикого, ни для мудреца. - Следовательно, к философии, тому знанию, которое имеет предметом душу, жизнь, мысль, радость и т.д., научный прием поправления и переопределения тех понятий, из которых состоит наука, неприложим» [ПСС 62, 222-223].

По сути дела, этим курсивом Толстой маркировал важнейшие экзистенциалы своей философии. Их нельзя подвергнуть рефлексии, то есть разложить на части. Ведь жизнь, смерть, разум, желания, - абсолютно цельные начала, «так как это понятия, приобретаемые непосредственно, и потому невозможно из этих понятий строить цепь какой бы то ни было необходимости <..> Все эти понятия не подлежат логическим выводам, все они равны между собой и не имеют логической связи <..> не достигаются логическими выводами, а достигаются только гармоничностью соединения в одно целое всех этих нелогических понятий, т.е. достигаются мгновенно, без выводов и доказательств и имеют только один прием доказательств - тот, что всякое другое, чем данное, соединение бессмысленно» [ПСС 62, 224]. Возможно это только благодаря искусству «сцепления», данных человеку интуитивно, возможно последующее разложение целого на части, и постигнутое интуицией, потом рассматривается рационально, 
представляя неразрывное начало: «круг или шар, у которого нет конца, середины и начала, самого главного или негативного, а всё начало, середина, всё одинаково важно и нужно» [ПСС 62, 225].

Таким образом, толстовскую философию можно представить как уникальное переходное учение от рационализма европейского Просвещения к антиметафизической религиозноэкзистенциальной философии начала XX в., не сводя ее ни к каким определенным философским направлениям. Особое значение имел для Толстого контекст своего времени как кризисной точки жизненного и идейного перехода его, по сути, транзиторного сознания.

О душевной чуждости Толстого современной философии, идеологии, политике, даже культуре, находящейся в зависимости в том числе и от его гениального творчества, писали не раз: «Что же касается позитивных идей Толстого - а они менялись на протяжении его долгой жизни значительно меньше, чем иногда пытаются представить, - они совсем не уникальны: кое-что роднит их с французским Просвещением XVIII века; кое-что - с идеями века XX; доминирующим идеям собственной эпохи он практически совершенно чужд. Он не принадлежал ни к одному из тех великих идеологических течений, на которые в годы его юности разделилось общественное мнение России. Он не был ни радикальным интеллектуалом откровенно прозападной ориентации, ни славянофилом, то есть сторонником христиансконационалистической монархии... Ближе всего ему был Руссо; он восхищался его взглядами больше, чем воззрениями любого другого современного автора» [Берлин 2001, 99].

Прот. А. Мень и вовсе считает его исключительно человеком эпохи Просвещения с его наивнейшей верою во всеобщую власть здравого смысла. «Он хотел упрощенную веру деизма объявить единственной истиной» [Мень 1995, 106].

Так ли уж очевидны его неукорененность в своем времени и существование в XVIII в.? Толстой, раскинувшись идейно и духовно по разным эпохам, был неразрывен именно со своим временем, сохраняя всю полноту не только отчуждения, но и сходства. Ядром его философии стало противоречие между искренней убежденностью в безграничных возможностях разума, пользуясь которым человек способен подняться до высот постижения высших истин, и нерациональным ощуцщением Бога в 

себе и в мире. Открыв в каждом наличие «общего чувства» как интуитивного основания жизни, он во многом отказался от просветительского рационализма и теории естественной природы и морали человека.

Понимал он и то, что «сегодняшний день» - это не иллюзорный мир восточной философии, от которого можно легко отмахнуться; это наш жизненный мир, где мы проживаем каждую секунду в суете и «генерализации мелочей» (Эйхенбаум), но живем для вечности. Как точно заметила Д. Лунгина, «вся дневниковая работа Толстого проникнута мыслью, что не существует вечного (будущего) помимо того, что идет уже сейчас. Как мыслитель нового, антиметафизического типа, Толстой был принципиальным противником потенциального в любых его проявлениях. Любое предписывающее - не важно, философское или теологическое - определение человека для него не имело смысла. Въевшаяся в плоть людей XIX века эта абстракция должна постоянно разрушаться под взглядом, который вырабатывает он в своем дневнике. Как религиозный мыслитель, Толстой апеллирует к разумности человека, понимая под этим непрерывную работу восприятия, по своей безусловной обязательности далеко перевешивающую умение оперировать готовыми идеями. В этом он смыкается с Керкегором, попадая вместе с ним в самую суть современной проблематики, а именно - что жизнь сама по себе есть острейшая проблема. И в этом таится не новый прихотливый виток развития философии, а необходимое, у Толстого на грани биологии, усилие человеческого спасения, усилие столь же автоматическое, сколь и трудное, и так же граничащее с абсурдом, как и керкегоровское требование существования» [Лунгина 2009, 53].

\section{Заключение}

Любовь к эпохе Просвещения не исключала приговора ее исторической и даже дискурсной ограниченности. Толстой был вполне солидарен с Н.Н. Страховым, высказавшим в одном из писем категорическое неприятие эпохи Просвещения (кстати, после прочтения Дидро): «А все-таки философы прошлого столетия едва ли стоят чтения. То есть, в них нельзя найти мыслей, соответствующих тому, что теперь мы называем серьезной мыслью. Даже Кант говорит языком и употребляет приемы рассуждения, которые нами уже оставлены» [Толстой, Страхов 2003, 867]. 
Наконец, отметим принципиальную разницу между Толстым и эпохой Просвещения в целом. Как было уже отмечено, стержневым отличием стала его жизненная религиозная позиция, мерками которой он мерил философов всех эпох, деля их на «настоящих» и «ненастоящих». Нежелание видеть в просветителях безбожников, коими многие были на самом деле, привело его к определению в качестве религиозных таких философов, как Спиноза и Дидро. «Религия и нравственность: еще недавно, в начале настоящего столетия, самые передовые люди если и отвергали католичество, как это делали энциклопедисты, то никто из них не отвергал того, что религия вообще была и есть необходимое условие для жизни каждого человека. Не говоря о деистах, как... Дидро и Руссо, Вольтер ставил памятник Богу, Робеспьер совершал празднество высшего существа» [ПСС 39, 5].

На самом деле взгляд его предшественников был эпохально иным. Для просветителей не важно было «на что я могу надеяться», главное - «что я могу знать», чтобы быть свободным, в том числе и от религии любого сорта; для Толстого же самый важный и стержневой вопрос жизни - это «как спасти душу», как соединить веру и разум в новое понимание жизни в Боге. При этом балансировать между секуляризмом и религией, просвещением и «толстовством» он мог лишь на пути создания принципиально иной религиозной философии, отличной от славянофильских и почвеннических доктрин XIX в., ставшей основой для поисков нового религиозного сознания и нового религиозно-философского учения. «Так что, кроме разумного знания, которое мне прежде представлялось единственным, я был неизбежно приведен к признанию того, что у всего живущего человечества есть еще какоето другое знание, неразумное - вера, дающая возможность жить. $<\ldots$.. > Вера есть сила жизни <..> искание бога было не рассуждение, но чувство, потому что это искание вытекало не из моего хода мыслей, - оно было даже прямо противоположно им, - но оно вытекало из сердца. Это было чувство страха, сиротливости, одиночества (курсив мой. - C. К.) среди всего чужого и надежды на чью-то помощь» [ПСС 23, 27-28].

Таким образом, эпоха Просвещения была чрезвычайно важна и значима для Толстого, но не только своими достижениями в области «здравомыслия» и идеалами природного человека и естественной нравственности, но и как завершающий эпохальный виток рождения новых горизонтов. Просвещение подготовило 

(а не уничтожило, как могло бы показаться из его антицерковных и антирелигиозных пассажей) новый взгляд на религиозноэтический и экзистенциальный тип личности в XX в.

\section{ПРИМЕЧАНИЯ}

(1) В 90-томном издании Полного собрания сочинений Толстого присутствуют девять ссылок на Д. Дидро. Имя французского просветителя упомянуто в «Войне и мире» [ПСС 12, 312], трижды в статье «Что такое искусство [ПСС 30, 44, 59, 518], в статье «Религия и нравственность» [ПСС 39, 5], в дневниках 1891 г. [ПСС 59, 15] и трижды в двух письмах к Н.Н. Страхову [ПСС 65, 276; ПСС 66, 13].

\section{ЦИТИРУЕМАЯ ЛИТЕРАТУРА \\ Асмус 1957 - Асмус В.Ф. Религиозно-философские трактаты} Л.Н. Толстого // Толстой Л.Н. Полное собрание сочинений в 90 т. Т. 23. - М.: Художественная литература, 1957.

Асмус 1971 - Асмус В.Ф. Диалектика необходимости и свободы у Спинозы // Асмус В.Ф. Избранные философские труды. Т. 2. - М.: МГУ, 1971.

Берлин 2001 - Берлин И. Толстой и просвещение // Берлин И. История свободы. Россия. - М.: НЛО, 2001

Дидро 1986 - Дидро Д. Мысли к истолкованию природы // Дидро Д. Сочинения в 2 т. Т.1. - М.: Мысль, 1986

Дидро 1986 - Дидро Д. О достаточности естественной религии // Дидро Д. Сочинения в 2 т. Т.1. - М.: Мысль, 1986.

Длугач 1975 - Длугач Т.Б. Дени Дидро. - М.: Мысль, 1975

Климова 2013 - Климова С.М. Теоремы разума и аксиомы веры. Спиноза и Толстой // Вопросы философии. 2013. № 6. С. 71-81.

Церковные ведомости 1901 - Церковные ведомости. 24 февраля 1901 г.

Толстой, Страхов 2003 - Толстой Л.Н., Страхов Н.Н. Полное собрание переписки в двух томах. - М.; Оттава, 2003

Лунгина 2009 - Лунгина Д.А. Современность в Дневниках Серена Керкегора и Льва Толстого // Логос. 2009. № 4-5 (72). С. 43-53.

Мень 1995 - Мень А., прт. Пустынь великого ересиарха. Религиозно-философские взгляды Л.Н. Толстого // Вышгород. 1995. № 5-6. C. 108-116.

Паперно 2018 - Паперно И. «Кто, Что Я?». Толстой в своих дневниках, письмах трактатах. - М.: НЛО, 2018

Спиноза 1957 - Спиноза Б. Избранные произведения в 2 т. - М.: Политиздат, 1957.

ПСС - Толстой Л.Н. Полное собрание сочинений в 90 т. - М.: Художественная литература, 1928-1958 (ссылки даются в квадратных скобках с указанием тома и страницы). 
Шульц 2013 - Шульц̧ С.A. Традиции Д. Дидро и готического романа в повести Л.Н. Толстого «Отец Сергий» // Русская литература. 2013. № 1. С. 111-130.

Эйхенбаум2009-Эйхенбаум Б.М. Молодой Толстой//ЭйхенбаумБ.М. Лев Толстой: исследования, статьи. - СПб.: Факультет филологии и искусств СПбГУ, 2009.

Bozovic 2018 - Bozovic M. Tolstoy and Diderot on Women as "Dangerous Objects" // Cicovacki P., Grek H.N. (Eds.) Tolstoy and Spirituality. Boston: Academic Studies Press, 2018.

Israel 2001 - Israel J.I. Radical Enlightenment. Philosophy and the Making of Modernity 1650-1750. - Oxford: Oxford University Press, 2001.

\section{REFERENCES}

Asmus V.F. (1957) L.N. Tolstoy's Religious-Philosophical Treatises. In: Tolstoy L.N. The Complete Collected Works in 90 Volumes (vol. 23). Moscow: Khudozhestvennaya literatura (in Russian).

Asmus V.F. (1971) Dialectics of Necessity and Freedom in Spinoza's Works. In: Asmus V.F. Selected Philosophical Works (vol. 2). Moscow: Moscow State University Pub. (in Russian).

Berlin I. (1960) Tolstoy and Enlightenment (Russian translation: Moscow: NLO, 2001).

Bozovic M. (2018) Tolstoy and Diderot on Women as "Dangerous Objects". In: Cicovacki P. \& Grek H.N. (Eds.) Tolstoy and Spirituality. Boston: Academic Studies Press.

Diderot D. (1986) Selected Works. Moscow: Mysl', 1986 (Russian translation).

Dlugach T. (1975) Denis Diderot. Moscow: Mysl', 1975 (in Russian).

Eikhenbaum B.M. (2009) Leo Tolstoy: Researches. Articles. Saint Petersburg: Saint Petersburg State University Pub. (in Russian)

Israel J.I. (2001) Radical Enlightenment. Philosophy and the Making of Modernity 1650-1750. Oxford: Oxford University Press.

Klimova S. (2013) The Theorems of Reason and the Axioms of Faith. Spinoza and Tolstoy. Voprosy filosofii. 2013. No. 6, pp. 71-81 (in Russian).

Tolstoy L. N. \& Strakhov N. N. (2003) Complete Collection of Correspondence in Two Volumes. Moscow (in Russian).

Lungina D. (2009) Modernity in the Diaries of Søren Kierkegaard and Leo Tolstoy. Logos. 2009. No. 4-5, pp. 43-53 (in Russian).

Men' A. (1995) Deserts of the Great Heresiarch. Religious-Philosophical Views by L. N. Tolstoy. Vyshgorod. 1995. No. 5-6, pp.108-116 (in Russian) 
Филос. науки / Russ. J. Philos. Sci. 2019. 62(2) Философская мысль в диалоге и полемике

Paperno I. (2014) “Who, What Am I?”: Tolstoy Struggles to Narrate the Self. Ithaca, NY: Cornell University Press (Russian translation: Moscow: NLO, 2018).

Schultz S.A. (2013) Traditions of D. Diderot and Gothic Novel in Leo Tolstoy's Novel "Father Sergius". Russkaya literatura. 2013. No. 1, pp. 111-130 (in Russian).

Spinoza B. (1957) Selected Works in 2 Volumes. Moscow: Nauka (Russian translation).

Tolstoy L.N. (1928-1958) Complete Collected Works in 90 Volumes. Moscow: Khudozhestvennaya literatura (in Russian). 